\title{
BINARY OR NON-BINARY? GENDER MORPHOLOGY IN SPANISH: DIFFERENCES DEPENDENT ON THE TASK
}

\author{
Gabriela Mariel ZUNINO \& Noelia Ayelén STETIE*1
}

\begin{abstract}
There is empirical evidence in different languages on how the computation of gender morphology during psycholinguistic processing affects the conformation of sex-generic representations. However, there is no empirical evidence on the processing of non-binary morphological variants in Spanish (-x or -e) in contrast to the generic masculine variant (-o). To analyze this phenomenon, we conducted two experiments: an acceptability judgment task and a sentence comprehension task. The results show differences depending on the task. This means that the underlying processes put into play in each one generate different effects. In acceptability judgments, which involve strategic processes mediated by beliefs and the linguistic norm, the generic masculine is more acceptable to refer to mixed groups. In the sentence comprehension task, which inquires about automatic processes and implicit representations, the non-binary forms consistently elicited a reference to mixed groups. Furthermore, the response times indicated that these morphological variants do not entail a higher processing cost than the generic masculine.
\end{abstract}

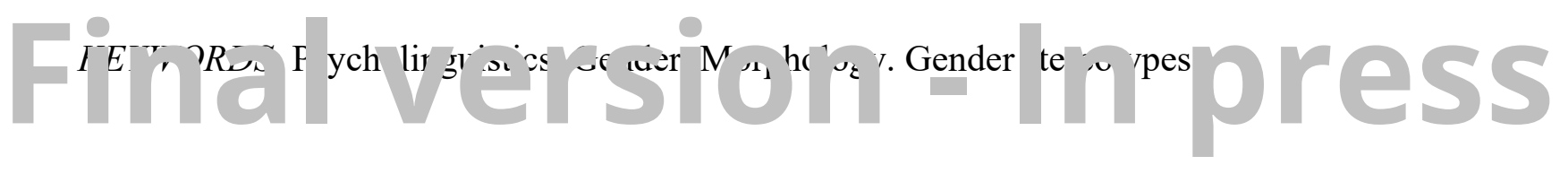

\section{Introduction}

The question of how language can influence thought in various ways dates back at least a century (SAPIR, 1921; ZLATEV; BLOMBERG, 2015). Through the years, and from different approaches -theoretical and empirical-, this problem has been taking different ways. Extreme forms of this idea, which sustained a linguistic determinism, more than an influence or bias, have provoked opposite reactions. Some of them, also extreme (PINKER, 1999), neglect intermediate approaches or proposals, also known as weak (EVERETT, 2013; LUCY, 1996; SAPIR, 1921; SCOTTO; PÉREZ, 2020; WHORF, 1956; ZLATEV; BLOMBERG, 2015). Initially, the linguistic relativity hypothesis held that the language we speak shapes the way we think. In other words, due to the different categories and distinctions that each language makes, especially semantic ones, its speakers are conditioned to pay attention to different aspects of

\footnotetext{
${ }^{1}$ Universidad de Buenos Aires (UBA) - Consejo Nacional de Investigaciones Científicas y Técnicas (CONICET), Instituto de Lingüística (FFyL- UBA), Buenos Aires, Argentina, gmzunino@conicet.gov.ar
} 
the environment. This would lead them, ultimately, to generate different representations of the same world events. Discarding a strong determinism does not mean ignoring the multiple and complex forms in which the relationship between thought and language -or cognition, mental representations and linguistic forms- may occur. There are, certainly, diverse and very current proposals concerning this issue (EVERETT, 2013; SCOTTO; PÉREZ 2020; ZLATEV; BLOMBERG, 2015): language as an "enhancer" of thought, language as an "intrusion" or "obstacle", language as a "focuser", language as an "inducer" and some variants of the wellknown thinking for speaking hypothesis (SLOBIN, 1991; 1996). Several of these perspectives have been taken up by empirical studies in the area of experimental psycholinguistics and have managed to collect substantial evidence to support some bias or influence of linguistic forms on cognition. Many studies on the projection of different languages' gender morphological marks toward sex-gender representations are conducted in this framework. These works investigate the possible gender bias that linguistic forms may bring to cognition.

Gender marks in languages are multiple and varied: they are found in both grammatical and lexical aspects. Beyond the structure of languages, the discursive uses of linguistic forms and the ways in which constructions are organized can also display various gender biases (LEAPER 2014; PÉREZ; MORAGAS, 2020; STAHLBERG et al., 2007). Thus, grammatical gender is

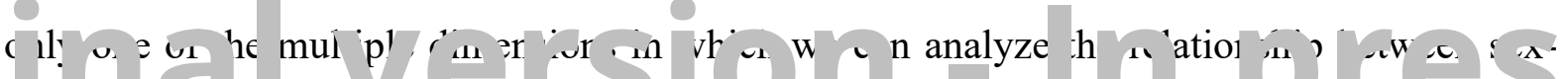
genuer representations, construction of meanngs lmked to gender ident its, and (uses or) language.

In this regard, it is necessary to begin by clarifying that languages vary in terms of how they mark grammatical gender. Over the years, different taxonomies have been proposed on the basis of grammatical gender (CORBETT, 1991; DIXON, 1987; LEAPER, 2014; PREWITTFREILINO; CASWELL; LAAKSO, 2012). The most recent is the one proposed by Gygax et al. (2019), which considers five types of languages: languages with grammatical gender, languages with natural gender, languages with a combination of grammatical and natural gender, and languages without gender -with some traces of grammatical gender and without traces-. Within the first group, where Spanish and other languages such as French, Polish and German are found, the gender controls the grammatical agreement and all nouns -referring to both animate and inanimate entities- have gender assigned. For example, in Spanish, most role names, which refer to people, are inflected for gender, such as secretaria [secretary.FEM] and secretario [secretary.MASC] or enfermera [nurse.FEM] and enfermero [nurse.MASC]. Grammatical gender is also assigned to inanimate objects, such as la leche [the.FEM milk] and el cartón [the.MASC cardboard]. 
A phenomenon studied is whether, for speakers of languages with obligatory gender marking and binary gender paradigms, the bias of generic interpretation ceases to be as arbitrary as grammatical studies suppose. That is, does the generic interpretation project representations associated with sex-generic identities of human entities to other words that refer to non-human entities? (EVERETT, 2013; FLAHERTY, 2001; KONISHI 1993; SAALBACH; IMAI; SCHALK, 2012; SEGEL; BORODITSKY, 2011; SERA et al., 2002).

Another of the most extensively studied points is the case of the so-called role names. Since these are instantiated differently in each language, depending on the grammatical gender paradigm (GYGAX et al., 2019), one question that arises is whether these different realizations generate different mental representations. In other words, as was suggested by Scotto and Pérez (2020), to what extent the influence of the grammatical gender of languages on cognition can be analyzed within the framework of the linguistic relativity hypothesis.

Experiments in different languages (KAUFMANN; BOHNER, 2014; LEAPER, 2014; SATO; GYGAX; GABRIEL, 2016; SCZESNY; MOSER; WOOD, 2015; VIGLIOCCO et al., 2005) have shown empirical evidence of stable biases - not contingent in particular linguistic uses or specific communicative contexts- of certain linguistic forms in cognition, namely in the mental representations that we manipulate during tasks, both mediated and not mediated by language.

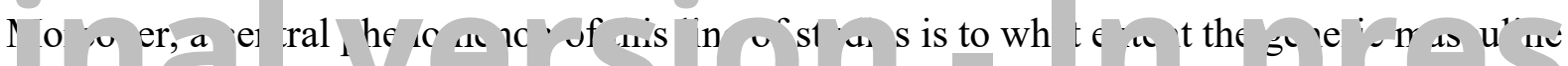
funciions as generic. 'Inat 1 , does it work for representing groups of peopl with non-unforin gender? In a binary gender paradigm, as in Spanish, the asymmetry between the uses of the feminine morphology to refer to exclusive groups of women is clear compared to the ambiguous uses of the masculine to refer to both groups of men and people with non-uniform gender identity (BRAUN; SCZESNY; STAHLBERG, 2005; CACCIARI; PADOVANI, 2007; GYGAX; GABRIEL, 2008, GYGAX et al., 2008, MACIUSZEK; POLAK; SWIATKOWSKA, 2019; MISERSKY; MAJID; SNIJDERS, 2019). Some works take this fact as another example that the feminine is the marked form (JIMÉNEZ RODRIGO; ONSALO; TRAVERSO CORTÉS, 2011; STAHLBERG et al., 2007). Some empirical studies in Spanish show that the bias generated by the generic masculine is identifiable and that it seems to have a sustained effect on cognition. For example, Kaufmann \& Bohner (2014), with a pioneering study in Spanish, analyzed the binary form with a bar (los/as) and two morphological innovations to generate inclusive non-binary forms (-@ and -x). In their experiment, participants had to read short stories and complete some fragments of different words. Although they found a weak bias in the completion modulated by participants' gender identity, they did not find differences due to the linguistic form used in the items. 
In this paper we develop the first stage of a broader line of research that tries to analyze how Spanish speakers process binary and non-binary morphological variants as ways of representing and referring to groups of people with non-uniform gender identity. In this sense, this study interacts with others that inquire about the cognitive projections of the generic masculine, but adds another phenomenon scarcely studied. We also analyze the psycholinguistic processing of the two morphological variants that a part of the community of Spanish speakers uses as non-binary morphological marks for nouns that refer to people (-x and -e). When we speak of non-binary forms here, we refer specifically to the morphological variants that are also known as gender-inclusive language ${ }^{2}$ : las niñas (girls) to refer to groups of women, los niños (boys) to refer to groups of men, and morphological innovations such as lxs niñxs or les niñes to refer to groups without uniform gender. The denomination itself can be disputed, and indeed it is. To avoid possible interpretations in which inclusive implies holding a binary norm as the core to only apply a third form as a way of encompassing what is supposed to be outside a hegemonic binarism, we will speak of non-binary (morphological) forms. Besides, we do not mean to reduce the notion of inclusive language to gender morphology.

Thus, we propose to analyze: 1. if the generic masculine in Spanish projects generic mental

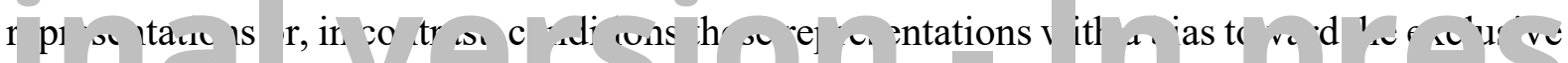

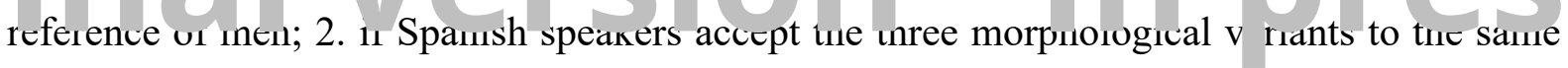
extent; 3. if non-binary morphological variants (-x and -e) adopted in Spanish manage to adequately represent non-uniform groups in their gender identity; 4. and if the processing cost to make that reference during sentence comprehension is greater for phrases with non-binary forms compared to the generic masculine form.

\section{Experiment 1}

As a first approach to the study of the phenomenon, we designed an acceptability judgments task. This would allow us to analyze the way in which speakers judge the acceptability of noun phrases based on two factors: the level of Stereotipicality of the role names involved and the type of Morphology used (binary and non-binary forms to refer to groups of people with nonuniform gender identity). Like any judgment task, this experiment investigates a strategic,

\footnotetext{
${ }^{2}$ Also known as non sexist language, gender-neutral language or gender-fair language.
} 
conscious and belief-mediated process that may exhibit different types of cultural biases. But we were especially interested, as a first step in this research, to have a measure of this type. In addition, this task allows us to verify if the levels of Stereotipicality considered a priori in the design are effectively projected as a determining factor for the speakers and if the items considered at each level respond adequately to that classification.

Our central hypothesis holds that acceptability judgments will vary depending on the level of Stereotipicality of the noun phrases according to the following pattern. On the one hand, we expect that, in the case of role names with low stereotipicality -los niños (the children)-, the generic masculine produces a more consistent reference to mixed groups of people. In the case of high stereotipicality -los plomeros (the plumbers)-, however, it would be less likely to interpret those noun phrases as appropriate to refer to a group that is not entirely conformed by men. Furthermore, our predictions assumed that non-binary forms would have more acceptance for the terms of low stereotipicality -les niñes meaning the children in the sens of boys and girls- than for those of medium and high stereotipicality -les plomeres [the plumbers. $\mathrm{NB}^{3}$ ]-, as the former phrases are used more often flexed with non-binary forms.

I ar ant.

Seventy-five people participated, 53 women (age: $M=32.55, S D=11.04$; range=18 and 62) and 22 men (age: $M=35.68 ; S D=11.03$; range=20 and 60). Of the total number of participants, 12 indicated that they had finished secondary school, 31 were undergraduate students, 29 had completed a college degree and 3 had postgraduate studies. All participants are speakers of Spanish as a first language and residents of Argentina.

\section{Materials}

The linguistic items used presented plural noun phrases $(\mathrm{DET}+\mathrm{N})$ that referred to groups of people. For the elaboration of the sentences, two variables with three levels each were considered. On the one hand, the Morphology: generic masculine (-o) and the two non-binary

\footnotetext{
${ }^{3} \mathrm{NB}=$ Non-binary morphological variant
} 
forms (-x and -e). On the other hand, the Stereotipicality (low, medium and high) of role names regarding their association to one gender or another, in a binary sex-generic system.

Six items were chosen for each level of Stereotipicality and were presented in the three morphological conditions that in Spanish could refer to groups of people without uniform gender. All three would correspond to morphological forms for generic plurals. To choose the items, it was considered that they admitted masculine and feminine heteronyms. Role names that did not present variation in gender -as los estudiantes (the students)- were avoided. Special care was also taken not to select words that required spelling changes when using the nonbinary form [-e] -as les amigues (friends)-. In addition, 6 more female items were included as fillers. The sentences were organized into 3 counterbalanced lists of 21 items each. Below are examples of the items used according to the level of Stereotipicality:

Low stereotipicality: Los hijos/Lxs hijxs/Les hijes (the children)

Medium stereotipicality: Los funcionarios/Lxs funcionarixs/Les funcionaries (the functionaries)

High stereotipicality: Los plomeros/Lxs plomerxs/Les plomeres (the plumbers)

I r a ir

The task was designed and taken through a Google form that randomly assigned a different list to each participant. In all cases, an informed consent was first submitted that had to be accepted to access the demographic questions and the experiment. Participants were asked to indicate gender identity, level of formal education and age. Then the instructions were presented. They had to judge the degree of acceptability of each sentence on a scale of 1 to 7 , with 1 being very low acceptability and 7 very high. Special emphasis was placed on the fact that the task should be carried out on the basis of understanding that phrase as a valid way to refer to a group of people without any gender distinction, that is, to refer to groups of people of non-uniform gender, or mixed groups.

The task was distributed through social media to potential participants who spoke Rioplatense Spanish, particularly in urban areas near Buenos Aires. Participation was voluntary and the participants did not receive any remuneration in return.

\section{Results}


The data analysis was carried out from the Likert scale scores of each participant for each noun phrase. The data was processed through the $R$ program version 4.1.1. in the $R$ Studio interface (R CORE TEAM, 2021). Several packages were used to perform statistical analysis: lme4 (BATES; MAECHLER; BOLKER; WALKER, 2015), lmerTest (KUZNETSOVA; BROCKHOFF; CHRISTENSEN, 2017) y MuMIn (BARTON, 2020).

Given the theoretical discussions about the best way to statistically treat data arising from scales, we followed Endresen and Janda (2015). We developed multiple different analyzes: ANOVA, Multiple Linear Regression, Mixed Model and Chi square. In all cases the pattern of results is similar and the statistically significant contrasts were the same.

In this case, we chose to report the results of the Linear Mixed Model (LMM) ${ }^{4}$. Each level of the fixed factors was coded as -0.5 and 0.5 , also known as scaled sum (SCHAD; VASISHTH; HOHENSTEIN; KLIEGL, 2020). Morphology and Stereotipicality were placed as fixed effects with interaction and the participant's Gender identity was nested to them. Participants and Items were placed as crossed random effects. The results of the model are shown in Table 1.

As can be seen in Figure 1 and 2, for both men and women, the pattern shows an acceptance scale. The phrases corresponding to high stereotipicality role names have a lower acceptance

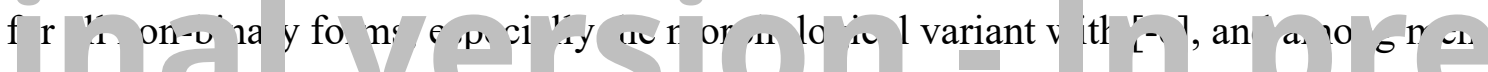

Figure 1 - Means of acceptability judgments by Figure 2 - High acceptability by Stereotipicality, Stereotipicality, Morphology and participants' Morphology and participant's Gender identity.

Gender identity.
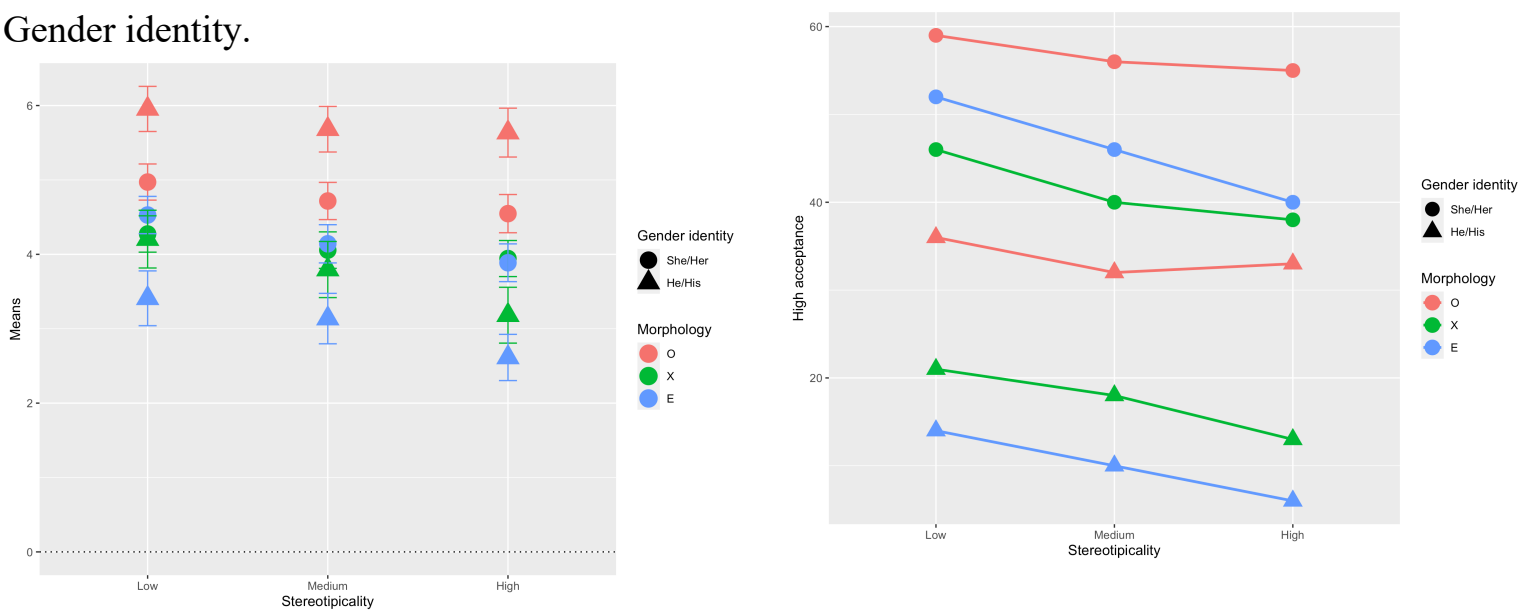

Table 1 - Report of the LMM

\footnotetext{
${ }^{4}$ In all analyses, the maximal model was tried first (BARR; LEVY; SCHEEPERS; TILY, 2013). If the model did not converge, we removed the random effects that accounted for the least variance in the nonconvergent maximal model until convergence was achieved.
} 


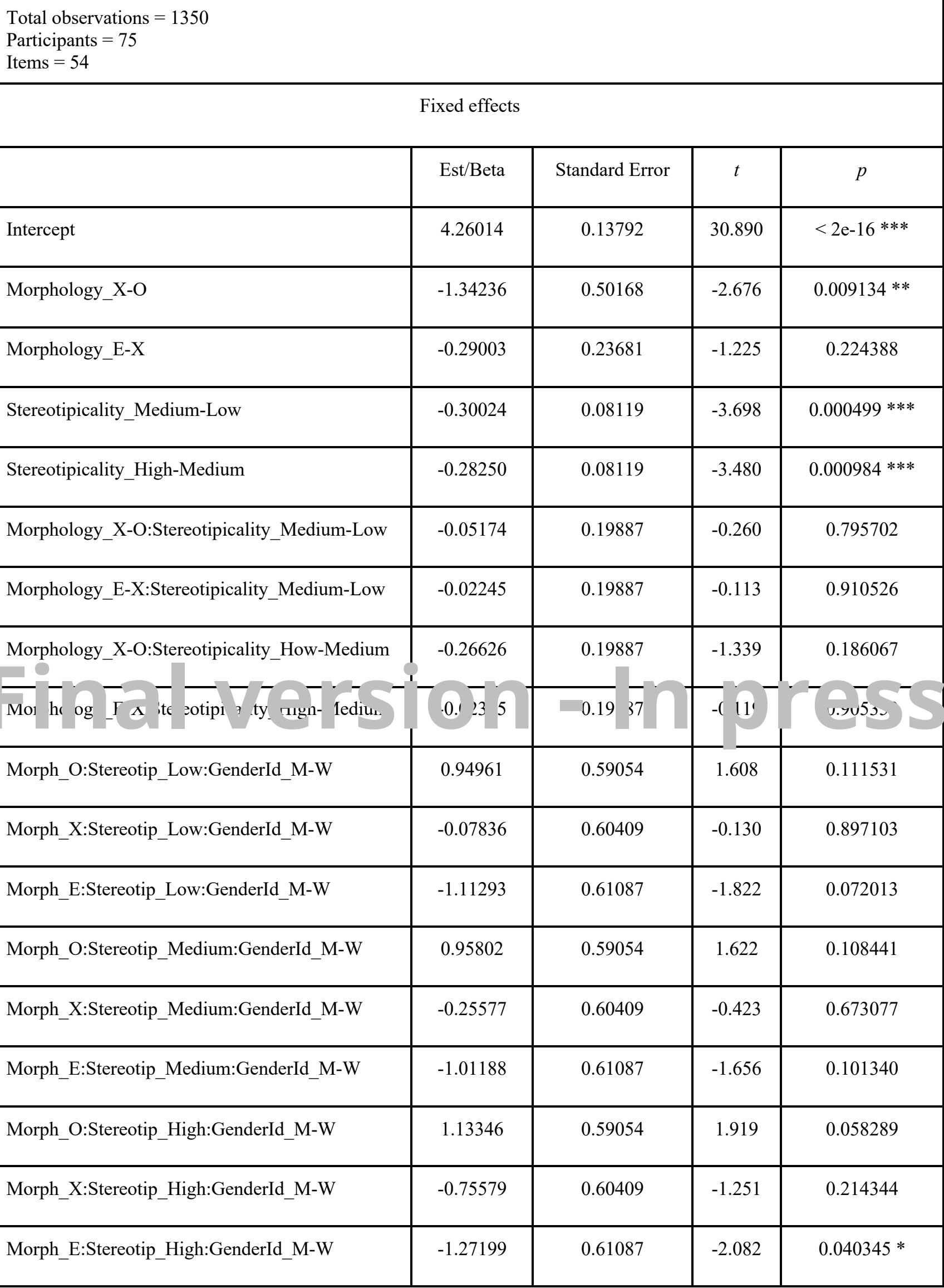




\begin{tabular}{|c|c|c|}
\hline \multicolumn{3}{|c|}{ Random Effects } \\
\hline & Variance & SD \\
\hline Participants (Intercept) & 1.11446 & 1.0557 \\
\hline Participants (Morphology_X-O) & 15.24133 & 3.9040 \\
\hline Participantes (Morphology E-X) & 3.07716 & 1.7542 \\
\hline Items (Intercept) & 0.01243 & 0.1115 \\
\hline \multicolumn{3}{|c|}{ Model fitting } \\
\hline \multirow[t]{2}{*}{$\mathrm{R}^{2}$} & Marginal & Conditional \\
\hline & 0.0769889 & 0.8538611 \\
\hline \multicolumn{3}{|c|}{$\begin{array}{l}\text { The p-values of the fixed effects were calculated with the Satterthwaite approximations. } \\
\text { Model equation: Acceptability } \sim(\text { Morphology * Stereotipicality }) / \text { Gender identity }+(1+\text { Morphology } \mid \text { Participants })+ \\
(1 \mid \text { Items })\end{array}$} \\
\hline
\end{tabular}

$\mathrm{M}=$ men; $\mathrm{W}=$ women.

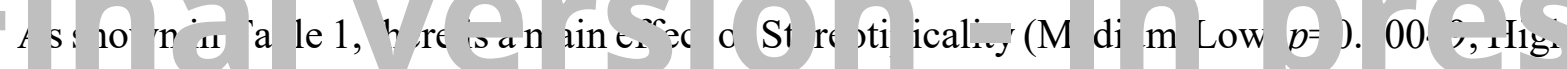

Medium: $p=0.000984)$. As for the generic morphological variants, statistically significant differences were found between the generic masculine form (-o) and both non-binary forms ( $p=0.009134)$, but not between the two non-binary variants $(p=0.224388)$. No interactions were found between Morphology and Stereotipicality ${ }^{5}$. Regarding the Gender identity variable, we found an effect nested to high stereotipicality to the non-binary variant [-e] $(p=0.040345)$ : women presented higher acceptance than men.

\section{Discussion}

Firstly, we were interested in using this task as a normative study to verify the levels of Stereotipicality considered a priori in our experimental design. According to our results, the items included in each level of this factor seem to be adequate.

\footnotetext{
${ }^{5}$ In addition, we ran a model in which we nested Stereotipicality to Morphology and found statistically significant differences for the non-binary forms, but not for the generic masculine.
} 
Secondly, as expected, Morphology showed a statistically significant effect. Non-binary forms were less accepted than the generic masculine form. Although the groups of men and women were unbalanced and there were no statistically significant differences between the two, a consistent pattern can be highlighted. Non-binary forms are less accepted among men than among women, in particular the morphological variant with [-e], the only one that presented statistically significant differences in the cases of high stereotipicality.

Finally, no statistically significant interactions were found between Stereotipicality and Morphology. However, the results showed a clear pattern: 1. role names with high stereotipicality -such as the plumbers- were less accepted when presented with non-binary forms -especially [-e]-; 2. the generic masculine was more accepted across the three levels of Stereotipicality; 3. the medium level of Stereotipicality seems to be the group with less consistent results (see Figures 1 and 2). A possible explanation for these results is that the more frequent use of non-binary forms generates more acceptance and that the words we categorize as high stereotipicality are not usually used in their non-binary morphological variants. But those we classify as medium stereotipicality seems to be, indeed, used more frequently with non-binary forms.

Acceptability judgment tasks involve strategic processes conditioned by linguistic ideologies,

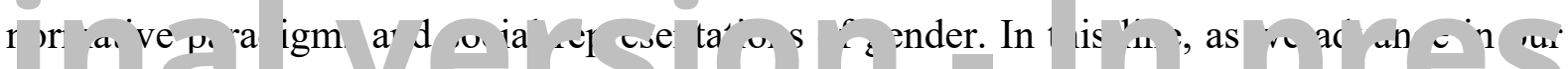
hypothesis, we can say that when tire task linvolves strategic processes str ingly mediatea vy beliefs and linguistic norm, the generic masculine is acceptable as a form to refer to mixed groups, over non-binary forms. The acceptability judgments are very relevant data, as they also show the conscious dispositions of the speakers in relation to the linguistic forms and their social uses. However, they may not allow us to verify what happens when the underlying mental processes involve manipulating gender representations in an implicit way and computing linguistic elements automatically during reading.

Our results show that when speakers must judge acceptability, as a conscious, voluntary and strategic process, the judgments reflect the support of binary forms and are in accordance with the norm that assumes that the Spanish generic masculine manages to refer to groups of people without gender identity bias. In order to analyze whether this tendency is maintained during automatic processes that require the manipulation of implicit sex-gender representations, and to evaluate the online psycholinguistic processing of these morphological forms -not only through precision or response type paradigms- we developed a second sentence comprehension experiment. 


\section{Experiment 2}

The second experiment was designed from the Stereotipicality classification of nominal phrases evaluated in Experiment 1. We analyzed the online psycholinguistic processing during sentence comprehension. It was expected to verify which were the implicit sex-gender representations that speakers constructed as reference for the noun phrases included as sujects of sentences during comprehension.

We designed a sentence comprehension task that involved reading a sentence at its own pace. Afterwards we presented a question about the possible reference of the nominal phrase in the subject position. The answer to this question was made through a multiple-choice paradigm. The central hypotheses for Experiment 2 assume that: 1. there will be an effect of the Stereotipicality of the role names for the selection of possible references; 2 . there will be an interaction between Stereotipicality and Morphology that will focus not only on the type of option chosen but also on the time it takes to make the choice; 3 . although the selection of referents of the non-binary forms will be more consistent toward groups with non-uniform gender, the time to make that choice may show an advantage for the generic masculine, as an l in in ed $10 \mathrm{~m} n \mathrm{~S}_{1}$ an sh

\section{Participants}

This task involved 551 people of whom 13 had to be removed (underage participants or subjects who did not declare their age). Of the remaining participants (538), 386 were women (age: $M=34.52 ; S D=11.60$; range=19 and 98), 131 were men (age: $M=34.15 ; S D=12.09 ;$ range=18 and 82 ) and 21 were identified as non-cisgender ${ }^{6}$ (age: $M=29.67 ; S D=8.21$; range=19 and 55). Of the total number of participants, 399 declared to live in the Metropolitan Area of Buenos Aires and 139 outside this area ${ }^{7}$. In terms of education, 34 participants declared that they had completed high school, 103 were undergraduate students, and 401 had completed a higher level degree or had postgraduate studies. Finally, they were asked if they used any form of non-

\footnotetext{
${ }^{6}$ The group of people we grouped under this denomination was composed of: non binaries, non binary girl, trans man, gay cis, none, nongender, fluid gender, lesbian, demi-girl, queer.

${ }^{7}$ This includes several provinces in Argentina.
} 
binary language and 136 stated that they did not, 111 that they used it little or occasionally and 291 that they used it frequently.

\section{Materials}

With the noun phrases used in the previous task, we elaborated sentences with them as syntactic subjects. The same experimental design was maintained and 18 sentences were created and presented in the three morphological variants. Below are examples for each condition of Stereotipicality:

Low Stereotipicality: Los/xs/es maestros/xs/es usan recursos variados durante la alfabetización inicial. (Teachers use a variety of resources during initial literacy training.) Medium Stereotipicality: Los/xs/es enfermeros/xs/es tienen obligación de actuar si hay un accidente en la vía pública. (Nurses have an obligation to act if there is an accident on the road.)

High Stereotipicality: Los/xs/es plomeros/xs/es con matrícula pueden hacer trabajos en edificios y consorcios. (Licensed plumbers can do work in buildings and consortiums.)

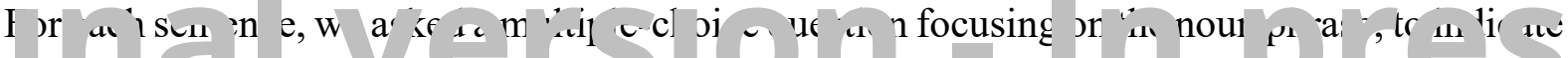
wherher it reiened to men, women ur nuxeu groups. In addition, three $m$ re answer uptiuns were added that acted as fillers. For this purpose, we used names that, in Argentina, are usually used with high frequency to name women or men. The following is a sample question and its response options:

¿A cuál de las siguientes opciones puede referir "los maestros”? (Which of the following options can "the teachers" refer to?)

a. Carolina.

b. Manuel.

c. Manuel, Marta y otras personas. (Manuel, Marta and other people)

d. Carolina, Marta y otras mujeres. (Carolina, Marta and other women)

e. Manuel, Federico y otros varones. (Manuel, Federico and other men)

f. Ninguna de las opciones anteriores. (None of the above)

Specifically, we were interested in measuring the distinction between options c. and e. in the previous example: the option that referred to a mixed group of people and the one that referred to a group of men. 
In addition, based on the fillers used in the previous task, 18 filler sentences were created with the nominal phrases in feminine. Also, 12 fillers that used the three generic variants, but presented a different comprehension question, were added. In this way, the exposure to diverse sentences and questions was balanced, to avoid learning or training within the task. For example:

Lxs pintorxs prefieren trabajar con óleos para conseguir mejores texturas y relieves. (The painters prefer to work with oil paints to get better textures and reliefs.)

¿Qué prefieren lxs pintorxs? (What do painters prefer?)

a. Trabajar con óleos. (To work with oil paints)

b. Pintar con acuarelas. (To paint with watercolors)

c. Usar muchos colores. (To use lots of colors)

d. Usar pinceles anchos. (To use wide brushes)

e. Realizar trazos finos. (To make fine strokes)

f. Ninguna de las opciones anteriores. (None of the above)

The stimuli were divided into three counterbalanced lists in which 2 items of each condition were included. Each list was formed by 48 items: 18 experimental and 30 fillers -the same for the three lists-.

\section{?}

\section{Procedure}

The task was designed and taken using PCIbex software (ZEHR; SCHWARZ, 2018), which randomly assigned a different list to each participant. In all cases, an informed consent form was first submitted and had to be accepted to access the demographic questions and the experiment. Participants were asked to indicate gender identity, highest level of education attained, age, nationality, city of residence, and how often they used non-binary morphological forms. They were then introduced with the instruction to first read the sentences, presented in black letters over white screen. Then, as a second screen, the question and response options were shown. Participants had to respond by selecting the option with the mouse. They were told to answer as quickly as possible based on their first impression. It was clarified that they would have three test sentences, followed by three more practice sentences, which for the participants were already part of the task. 
The experiment was distributed through social media among Spanish speakers, preferably the Rioplatense variety. Participation was voluntary and participants received no remuneration in return.

\section{Results}

\section{Analysis of response types}

The data were analyzed with the same programs and packages as in Experiment 1. For the analysis of response times and types, we only considered those corresponding to the items answered correctly. That is, we considered only those responses that referred to a group of men or a mixed group of people, and discarded those that referred to a single person, a group of women or none of the above. Of the eliminated responses, none referred to a single person neither by a typically female nor a typically male name-, 51 referred to a group of women and 342 referred to none of the above ${ }^{8}$. The items discarded for incorrect answers represent $4.06 \%$ of the data.

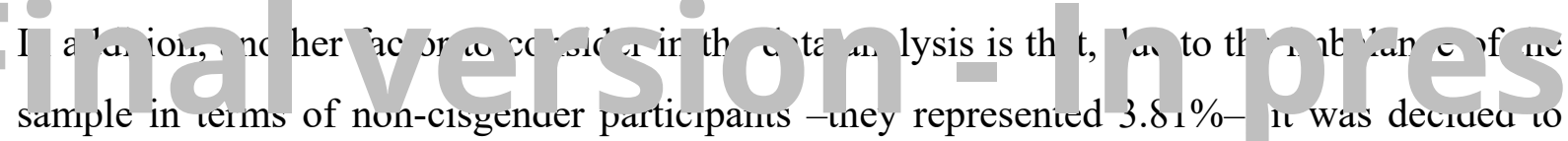
remove them for the statistical models, but not for the figures, in order to begin to outline the differences of this particular group, to continue their analysis in future works. .

As can be seen in Figure 3 and Table 2, both non-binary morphological variants (-x and -e) consistently generate an unequivocal representation and reference to mixed groups of people, regardless of the level of stereotipicality of the role name. However, the same does not hold up to the generic masculine. First of all, it would seem not to work unequivocally as a generic form. Secondly, the representation and reference that are constructed would seem to depend on

\footnotetext{
${ }^{8}$ A more detailed analysis of those answers marked as "none" reveals that this option was mostly used to answer sentences in non-binary language -162 answers to sentences with the [-e] variant and 158 to sentences with the [x] variant-. Since of these 320 answers, 279 belonged to people who had declared not to use any non-binary language form, we consider that this was a way of pointing out that non-binary language forms cannot be understood. In addition, of the 342 responses, $221(64.62 \%)$ referred to persons identified as cis women, 116 $(33.92 \%)$ referred to persons identified as cis men, and $5(1.46 \%)$ referred to a person identified as non-cisgender. Of the remainder, we believe that it was an error due to lack of attention. We evaluated the possibility that, with these answers, participants wanted to point out that the non-binary form does not refer only to men and women, but also to non-cisgender people, but this hypotheses was later discarded because the option that referred to a mixed group of people included stereotypical names used for women, others used for men and the clarification "and other people".
} 
the level of Stereotipicality: those names with low stereotipicality -such as los niños (the children) or los maestros (the teachers)- generate more effectively generic representations, while those with high stereotipicality -such as los plomeros (the plumbers) or los herreros (the blacksmiths)-generate eminently masculine representations.

Figure 3 - Response type by Stereotipicality and Morphology

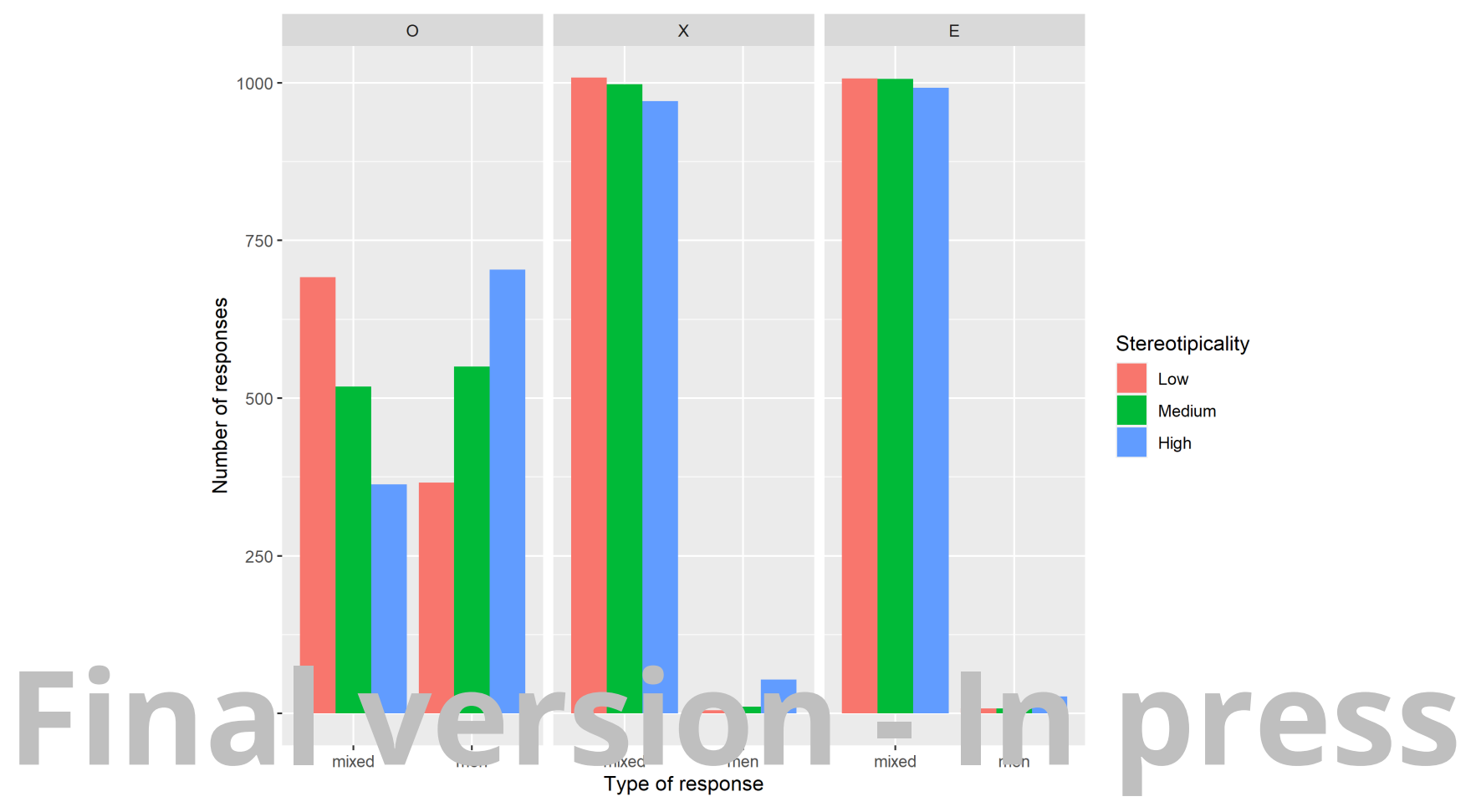

Also, as can be seen in Table 3, these representations seem to vary according to the participant's Gender identity. First, although the responses of women and men for both options go in the same direction, among women the preference for a masculine reference is even stronger as the stereotipicality of role names increases. Second, for participants identified as non-cisgender, the [-o] variant would seem not to generate effectively generic representations even when the stereotipicality of role names is low.

Table 2 - Response type by condition (\%)

\begin{tabular}{|l|c|c|c|c|c|c|}
\hline \multirow{2}{*}{} & \multicolumn{9}{|c|}{ Stereotipicality } \\
\cline { 2 - 7 } & \multicolumn{2}{|c|}{ Low } & \multicolumn{2}{c|}{ Medium } & \multicolumn{2}{c|}{ High } \\
\hline Response type & Mixed & Men & Mixed & Men & Mixed & Men \\
\hline
\end{tabular}




\begin{tabular}{|l|l|l|l|l|l|l|}
\hline Morphology-O & $65,41 \%$ & $34,59 \%$ & $48,50 \%$ & $51,50 \%$ & $34,02 \%$ & $65,98 \%$ \\
\hline Morphology-X & $99,51 \%$ & $0,49 \%$ & $98,91 \%$ & $1,09 \%$ & $94,73 \%$ & $5,27 \%$ \\
\hline Morphology-E & $99,21 \%$ & $0,79 \%$ & $99,21 \%$ & $0,79 \%$ & $97,35 \%$ & $2,65 \%$ \\
\hline
\end{tabular}

Table 3 - Response type for [-o] morphological variant (generic masculine)

\begin{tabular}{|l|c|c|c|c|c|c|}
\hline \multirow{2}{*}{} & \multicolumn{5}{|c|}{ Stereotipicality } \\
\cline { 2 - 8 } & \multicolumn{2}{|c|}{ Low } & \multicolumn{2}{c|}{ Medium } & \multicolumn{2}{c|}{ High } \\
\hline Response type & Mixed & Men & Mixed & Men & Mixed & Men \\
\hline Gender identity-Women & $63,95 \%$ & $36,05 \%$ & $45,96 \%$ & $54,04 \%$ & $30,12 \%$ & $69,88 \%$ \\
\hline Gender identity-Nen & $74,61 \%$ & $25,39 \%$ & $59,85 \%$ & $40,15 \%$ & $48,26 \%$ & $51,74 \%$ \\
\hline Gender identity- Non-cisgender & $35,71 \%$ & $64,29 \%$ & $24,39 \%$ & $75,61 \%$ & $17,07 \%$ & $82,93 \%$ \\
\hline
\end{tabular}

Due to the characteristics of the phrases in non-binary language and the differences in the

Response type presented in Tables 2 and 3, the statistical analyses were carried out in two separte ways. First, on the mixed responses and, secondly, on the generic masculine responses, the only ones that effectively enabled a response by a group of men.

As shown in Table 2, there was a statistically significant difference in the mixed responses according to the Morphology for low $\left(X^{2}(2, \mathrm{~N}=3086)=744.03, p=<2.2 \mathrm{e}-16\right)$, medium $\left(X^{2}(2\right.$, $\mathrm{N}=3091)=1189.6, p=<2.2 \mathrm{e}-16)$ and high $\left(X^{2}(2, \mathrm{~N}=3111)=1431, p=<2.2 \mathrm{e}-16\right)$ stereotipicality. In all three cases, the differences were between the generic masculine and both non-binary forms.

For the analysis of the responses of the generic masculine, we used a GLM (Generalized Linear Model) since it was a dichotomous variable -response by mixed groups or groups of men-. The percentages in Table 3 suggest that there was no interaction between Gender identity and Stereotipicality. However, as for the correlation between Gender identity and Frequency of use, this analysis would require fitting a model with more factors than we can develop in this paper. Table 4 presents the results of the statistical model chosen to explain the data obtained. 
Table 4 - Report of the GLM

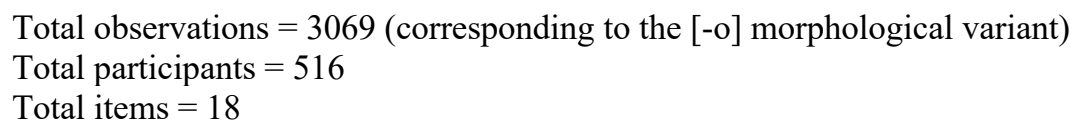

Fixed effects

\begin{tabular}{|l|c|c|c|c|}
\hline & Est/Beta & Standard error & $z \quad p$ & 0.0729 \\
\hline Intercept & -0.4348 & 0.2425 & -1.794 & 5.604 \\
\hline Stereotipicality_Medium-Low & 1.8924 & 0.3377 & $2.10 \mathrm{e}-08 * * *$ \\
\hline Stereotipicality_High-Medium & 1.5980 & 0.3334 & 4.793 & $1.64 \mathrm{e}-06 * * *$ \\
\hline Gender identity_Men-Women & -1.7189 & 0.4284 & -4.012 & $6.01 \mathrm{e}-05 * * *$ \\
\hline
\end{tabular}

Random effects

\begin{tabular}{|c|c|c|}
\hline & Variance & SD \\
\hline Participants (Intercept) & 13.0154 & 3.6077 \\
\hline
\end{tabular}

Model fit

\begin{tabular}{|l|c|c|}
\hline $\mathrm{R}^{2}$ & Marginal & Conditional \\
\hline & 0.1351304 & 0.8282188 \\
\hline
\end{tabular}

Model equation: Response type $\sim$ Stereotipicality + Gender identity $+(1 \mid$ Participants $)+(1 \mid$ Items $)$

As can be seen from Table 4, two main effects were found: one linked to Stereotipicality and the other linked to the participants' Gender identity. These effects confirm the differences shown in Table 3. The difference between responses by a mixed group or a group of men exhibits a main effect of Stereotipicality (Medium-Low: $p=2.10 \mathrm{e}-08$; High-Medium: $p=1.64 \mathrm{e}-$ $06)$. Additionally, the data show an effect of Gender identity $(p=6.01 \mathrm{e}-05)$. 
For the analysis of the response times, we carried out an identification of outliers and then a logarithmic transformation. Measures that were more than $2.5 \mathrm{SD}$ from the mean by condition were replaced by the mean of each participant in each condition. This involved replacing 245 data points, that is $2.64 \%$ of the sample (BAAYEN; MILIN, 2010; COUSINEAU; CHARTIER, 2010; RATCLIFF, 1993).

In addition, before performing the statistical analyses, response times were plotted by condition in order to visually identify if there was any general pattern in the data. Figure 4 and Table 5 show the response times by Response type, Morphology, Stereotipicality of role names, and participants' Gender identity ${ }^{9}$. For responses that referred to a mixed group of people, the times pattern between women and men is similar, while the pattern of participants identified as noncisgender is different. In relation to responses that referred to a group of men, the non-cisgender participants did not, in any case, indicate that phrases with the non-binary [-e] variant could refer to this response type.

Figure 4 - Response times by Response type, Gender identity, Stereotipicality and Morphology

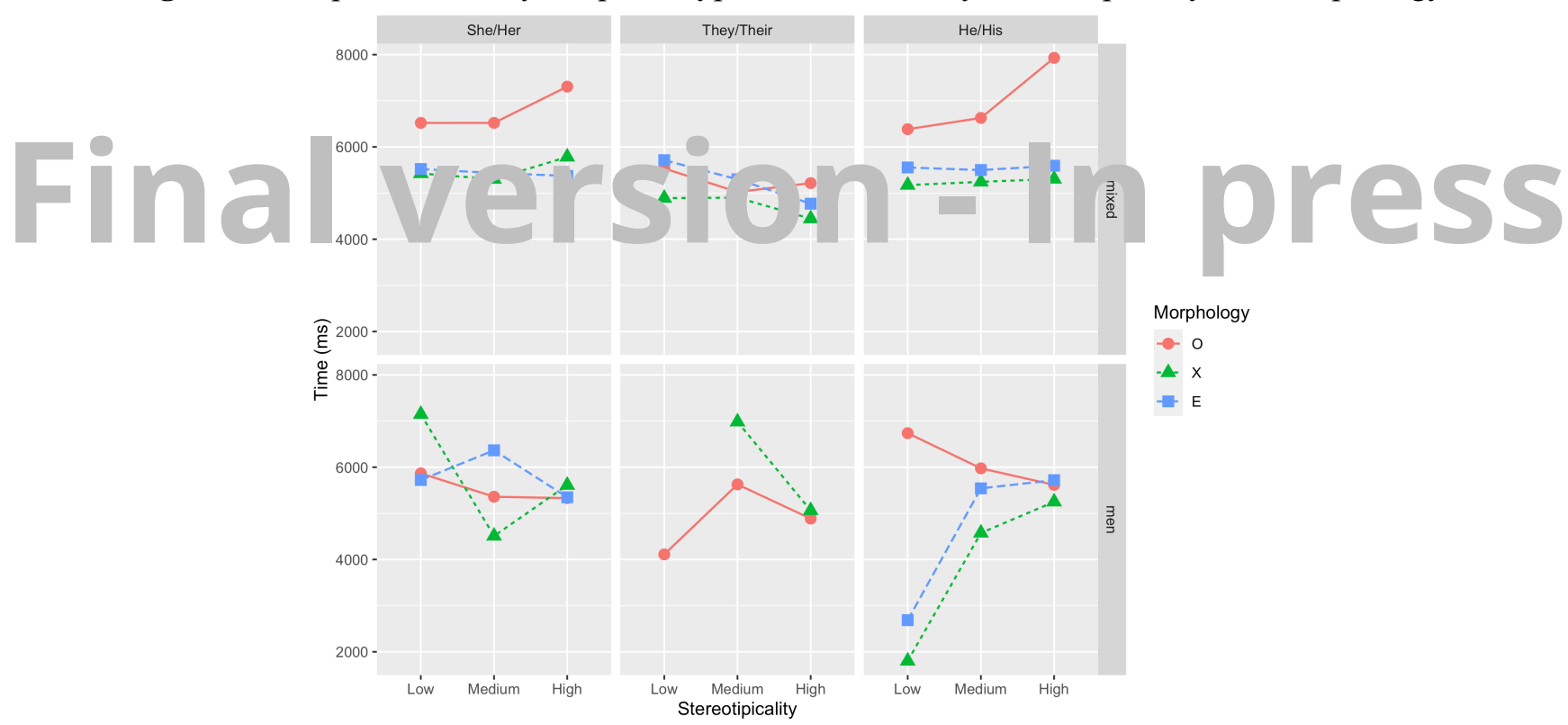

Table 5 - Means and standard deviation of response times by Gender identity, Response type, Stereotipicality and Morphology.

\begin{tabular}{|l|l|l|}
\hline \multicolumn{2}{|c|}{ Women } \\
\hline Resp & Mixed & Men \\
\hline
\end{tabular}

\footnotetext{
${ }^{9}$ In a complementary analysis, we studied the relationship between Gender identity and Frequency of spontaneous use of non-binary forms, reported by the participants. Due to the complexity of this analysis and the space restrictions in the present work, we decided to develop this point in Zunino and Stetie (submitted).
} 


\begin{tabular}{|c|c|c|c|c|c|c|}
\hline St & Low & Medium & High & Low & Medium & High \\
\hline RT & $M(S D)$ & $M(S D)$ & $M(S D)$ & $M(S D)$ & $M(S D)$ & $M(S D)$ \\
\hline$-\mathrm{O}$ & $6520(3558)$ & $6520(3818)$ & $7306(4166)$ & $5867(3274)$ & $5359(3482)$ & $5329(3302)$ \\
\hline$-\mathrm{X}$ & $5424(2430)$ & $5301(2439)$ & $5782(3022)$ & 7147 (3591) & $4509(2080)$ & $5609(3750)$ \\
\hline$-\mathrm{e}$ & $5521(2494)$ & $5434(2495)$ & $5371(2426)$ & $5722(2963)$ & $6365(4646)$ & $5348(2646)$ \\
\hline \multicolumn{7}{|c|}{ Men } \\
\hline Resp & \multicolumn{3}{|c|}{ Mixed } & \multicolumn{3}{|c|}{ Men } \\
\hline St & Low & Medium & High & Baja & Media & Alta \\
\hline RT & $M(S D)$ & $M(S D)$ & $M(S D)$ & $M(S D)$ & $M(S D)$ & $M(S D)$ \\
\hline$-\mathrm{O}$ & $6383(3073)$ & $6628(3423)$ & $7930(5233)$ & 6737 (4169) & $5975(3558)$ & $5616(4486)$ \\
\hline$-\mathrm{X}$ & $5172(2311)$ & $5243(2268)$ & $5304(2460)$ & $1801(-)$ & $4575(-)$ & 5249 (5539) \\
\hline$-\mathrm{e}$ & $5554(2498)$ & $5498(2516)$ & $5591(2595)$ & $2685(77)$ & $5541(368)$ & $5719(3754)$ \\
\hline \multicolumn{7}{|c|}{ Non-cisgender } \\
\hline St & Low & Medium & High & Low & Medium & High \\
\hline RT & $M(S D)$ & $M(S D)$ & $M(S D)$ & $M(S D)$ & $M(S D)$ & $M(S D)$ \\
\hline-0 & $5532(1372)$ & $5024(1448)$ & $5215(2224)$ & $4110(1712)$ & $5627(3900)$ & $4885(2346)$ \\
\hline$-\mathrm{X}$ & $4890(1901)$ & $4900(2642)$ & 4444 (1637) & - & $6984(-)$ & $5061(3776)$ \\
\hline$-\mathrm{e}$ & $5712(2793)$ & $5298(2240)$ & $4769(1865)$ & - & - & - \\
\hline
\end{tabular}

Resp= Response type; RT=Response Time; $\mathrm{St}=$ Stereotipicality; $\mathrm{M}=$ mean; SD=Standard deviation

Taking into account the experimental hypotheses, we run a LMM with Morphology and Gender identity as fixed effects and Stereotipicality and Response Type nested to Morphology. Participants and Items were placed as random effects. Table 6 reports the results of the statistical model.

Table 6 - Report of the LMM 
Total observations $=8917$

Total participants $=517$

Total items $=54$

Fixed effects

\begin{tabular}{|c|c|c|c|c|}
\hline & Est/Beta & Standard error & $t$ & $p$ \\
\hline Intercept & 8.55328 & 0.02583 & 331.147 & $<2 \mathrm{e}-16 * * *$ \\
\hline Morphology_X-O & -0.15133 & 0.04752 & -3.185 & $0.00146 * *$ \\
\hline Morphology_E-X & 0.08460 & 0.06330 & 1.337 & 0.18143 \\
\hline Gender identity_Men-Women & 0.01405 & 0.02891 & 0.486 & 0.62721 \\
\hline Morphology_O:Stereotipicality_Medium-Low & -0.05422 & 0.02700 & -2.008 & $0.04968 *$ \\
\hline Morphology_X:Stereotipicality_Medium-Low & -0.11135 & 0.13300 & -0.837 & 0.40250 \\
\hline Morphology_E:Stereotipicality_Medium-Low & 0.24803 & 0.12173 & 2.038 & $0.04164 *$ \\
\hline Morphology_O:Stereotipicality_High-Medium & 0.04921 & 0.02685 & 1.833 & 0.07255 \\
\hline Mor] 10 gy $X$ st ec pical $\vee H$ n-Ivle ium & ( $) 8 ; 3$ & v.084 6 & 0.95 & \\
\hline Morphology_E:Stereotipicality_High-Medium & -0.22044 & 0.09797 & -2.250 & $0.02448 *$ \\
\hline $\begin{array}{l}\text { Morphology_O:Stereot_Low:Resp_Men- } \\
\text { Mixed }\end{array}$ & -0.07574 & 0.03272 & -2.315 & $0.02062 *$ \\
\hline $\begin{array}{l}\text { Morphology_X:Stereot_Low:Resp_Men- } \\
\text { Mixed }\end{array}$ & 0.01634 & 0.21530 & 0.076 & 0.93951 \\
\hline $\begin{array}{l}\text { Morphology_E:Stereot_Low:Resp_Men- } \\
\text { Mixed }\end{array}$ & -0.17557 & 0.17182 & -1.022 & 0.30689 \\
\hline $\begin{array}{l}\text { Morphology_O:Ste_Medium:Resp_Men- } \\
\text { Mixed }\end{array}$ & -0.19544 & 0.03069 & -6.368 & $2.01 \mathrm{e}-10 * * *$ \\
\hline $\begin{array}{l}\text { Morphology_X:Ste_Medium:Resp_Men- } \\
\text { Mixed }\end{array}$ & -0.18820 & 0.15305 & -1.230 & 0.21887 \\
\hline $\begin{array}{l}\text { Morphology_E:Ste_Medium:Resp_Men- } \\
\text { Mixed }\end{array}$ & 0.37172 & 0.17105 & 2.173 & $0.02979 *$ \\
\hline $\begin{array}{l}\text { Morphology_O:Stereo_High:Resp_Men- } \\
\text { Mixed }\end{array}$ & -0.33894 & 0.03223 & -10.515 & $<2 \mathrm{e}-16 * * *$ \\
\hline $\begin{array}{l}\text { Morphology_X:Stereo_High:Resp_Men- } \\
\text { Mixed }\end{array}$ & -0.11716 & 0.06936 & -1.689 & 0.09123 \\
\hline
\end{tabular}




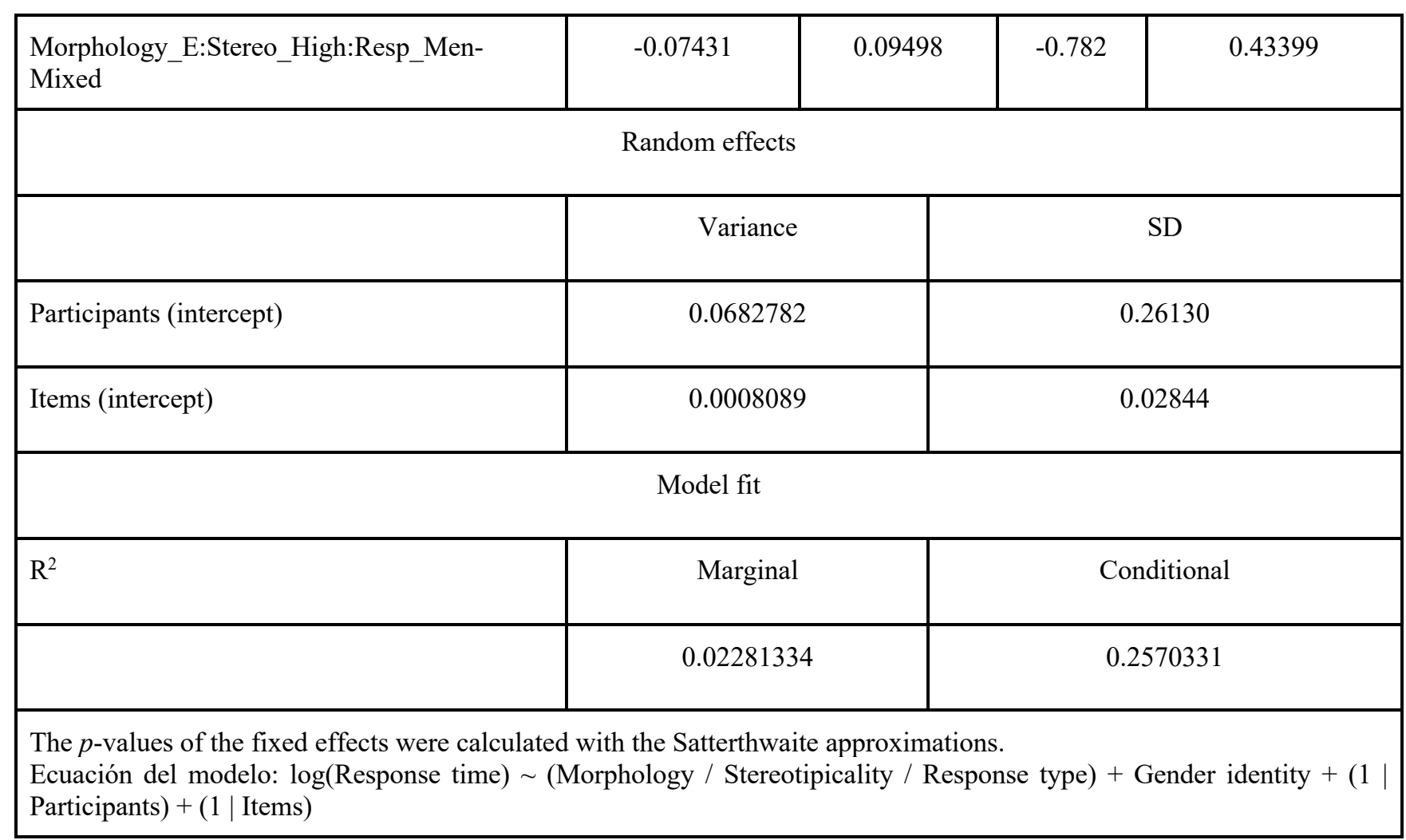

\section{Resp= Response type}

In the reported model (Table 6), a main effect of Morphology was found in favor of the non-

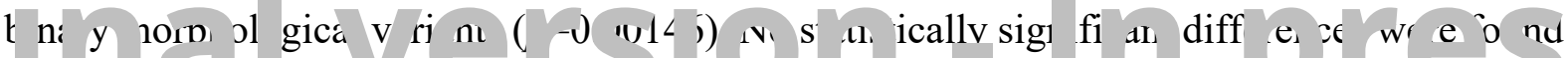
between both non-binary varıants $(p=0.18143)$. No main effect of partıcipal s Gender 1aentıty was found $(p=0.62721)^{10}$. As for Stereotipicality, a nested effect was found for Morphology, in particular for the morphological variant [-e]. Regarding Response type, statistically significant differences were found nested to the generic masculine at all levels of Stereotipicality.

Finally, it is worth mentioning that, because we requested various demographic data, we were able to investigate possible effects of the participants' level of formal schooling: no significant effects were found for this factor. With respect to age, on the other hand, the sample was diverse. This, on the one hand, avoided projecting anomalous results that usually arise from WEIRD samples (HENRICH; HEINE; NORENZAYAN, 2010), but, on the other hand, it did not allow us to generate homogeneous and balanced subgroups to perform adequate contrasts

\footnotetext{
${ }^{10}$ We tried running a more complex statistical model with the other factors nested within Gender identity, but this model did not converge. However, we did a segmented analysis and found that there were statistically significant differences between men and women only for the response type to generic masculine with low stereotipicality. As seen in Figure 4, women took longer to assign a mixed reference to the generic masculine with low stereotipicality.
} 
with respect to this variable. We plan to focus on this factor in future experiments considering Age as part of the initial experimental design.

\section{Discussion}

Unlike the first task, this second experiment shows automatic processes during language comprehension and their relationship with implicit or unconscious gender representations.

Firstly, it is interesting to note the distribution of the response types. As we mentioned in the Results section, the first point to take into account is the modulation that the Stereotipicality of role names exerts on the choices of possible referents when the nominal phrase was presented in the [-o] variant, that is, the generic masculine. This modulation does not occur for either of the non-binary morphological forms. Consequently, we can point out that the non-binary forms seem to function as specific linguistic and semantic marks that are more precise and unequivocal with respect to their referential capacity. Although the role name is more or less associated with a given sex-gender identity, both non-binary forms seem to consistently generate representations of groups of people without a uniform gender. This is not, however,

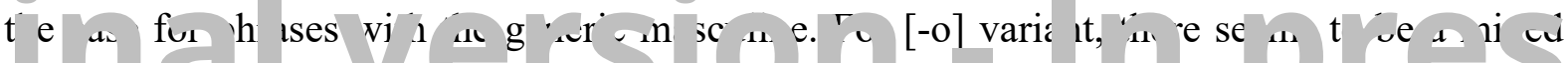
repiesentauon only wnen a ıvie namı is not suongly associated a priori wi i some sex-genuer identity or gender stereotype. In other words, if we want to refer to mixed groups of people whose profession is, for example, plumbing, using the generic masculine would not generate that mixed representation. On the other hand, using any of the non-binary forms would generate representations of mixed groups.

Secondly, it is necessary to analyze the results linked to the online response selection process, that is, the time it takes to make the choice of an option for each reference. In this sense, the interpretation of these data implies understanding the response time as a reflection of the process that leads to the construction or recovery of a sex-gender mental representation suitable for each nominal phrase that allows the generation of a valid reference.

A first point that should be highlighted is that Morphology generated a main effect on response times, but in the opposite direction to the one we hypothesized. Furthermore, it showed a different pattern from the one exhibited by the acceptability judgments in Experiment 1. Phrases with generic masculine required greater response times than those exhibited with either of the two non-binary morphological variants. Within the non-binary variants, no statistically significant differences were found. The generic masculine is distinguished from the non-binary 
forms, but, at least in written text, the [-x] and [-e] variants show no difference in the speed required to manipulate a mental representation and generate a reference to mixed or nonuniform gender groups. It is important to note that this internal pattern of the non-binary forms is similar to the one found for acceptability judgments. However, it is necessary to develop studies that investigate oral statements processing and forms that require spelling changes, since that is where the major difference between these two variants could be located.

If we analyze the response times in each of the three morphological variants, we note that women who choose a reference to mixed groups from a generic masculine nominal phrase, particularly low stereotipicality, take longer to make that choice than men. However, for both groups, there is a similar pattern when comparing the choice of mixed reference with generic masculine with respect to the reference to men exclusively. So, in cases where the generic morphology is ambiguous, answering for a mixed option takes more time, that is, it exhibits a higher processing cost. This same interpretation will be supported by a similar effect arising from the effect of Stereotipicality, which we will comment on later.

We can say, then, that when we understand phrases with generic masculine [-o] as constructing a reference to groups formed by people of different genders is not only more costly in terms of the final result of that reference -response type, precision in the mixed reference- but also in

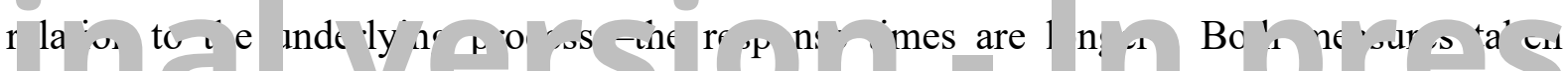
together build a pattern. Ivon-vinary variants enabıe unequivucaı and c nsistent rererence toward mixed groups. Also the times required for that process are shorter for those cases of unambiguous references than for those with the generic masculine, that generates an ambiguous reference between exclusive groups of men or mixed groups. In this last case, both representations could be competing.

Moreover, Stereotipicality resulted in a modulating effect of the process when it is analyzed according to the response type. In general, the medium level of Stereotipicality is not significantly different from the other two levels, so there seems to be support for considering that this medium level may be exhibiting a diachronic and gradual process of greater use of non-binary forms for those phrases. We propose a sort of frequency effect of exposure to phrases such as lxs funcionarixs [functionaries.NB] in their non-binary form -a frequency, in this synchronic cut, lower than that of, for example, lxs niñxs-. There is also an effect of Response type nested to the morphological variant [-o] for the three levels of Stereotipicality. Assigning a mixed reference showed higher processing costs, with significantly longer response times, with respect to responses that exhibit an exclusive masculine reference. We can interpret, then, that for role names with strong sex-gender associations, the generic 
masculine produce a first default bias toward the exclusive male interpretation. So, arriving at a mixed interpretation may involve a second stage in processing, with possible revisions or monitoring.

Finally, we want to focus on the analysis of participants' Gender identity. Although in the two groups identified as cisgender, the generic masculine shows longer response times, the general pattern shown in Figure 4 shows some particularities for each case. Only 21 participants were identified as non-cisgender, and only that group shows a different pattern of response times and types. When we analyzed the statistical models with only two levels of gender identity men and women- we noticed that the significant differences due to that factor were eliminated and the pattern of response times did not vary according to the participants' Gender identity. We can say that during processes strongly associated with levels of automatic processing and unconscious or implicit manipulation of mental representations, the underlying psycholinguistic process exhibited by women and men is similar. This is so even when in strategic tasks, mediated by linguistic ideologies and explicit sex-gender representations, differences may exist due to this factor. This seems to be one of the key points in analyzing differences due to the task, a phenomenon that we will return to in the General discussion.

\section{Fina}

As we mentioned in the Introduction, there are no studies that analyze the psycholinguistic processing of non-binary forms in Spanish. There are some studies on perceptions, beliefs and evaluation of linguistics uses with and without gender bias in Spanish and other languages (JIMÉNEZ RODRIGO; ONSALO; TRAVERSO CORTÉS, 2011; KAUFMANN; BOHNER, 2014; LEAPER, 2014; PREWITT-FREILINO; CASWELL; LAAKSO, 2012). However, there are no studies that strictly inquired about the levels of acceptability of specific phrases with non-binary morphological variants.

With this study, we are interested not only in beginning to analyze these phenomena with greater systematicity, but also in studying the differences that may arise due to the task, or rather, the underlying process involved in carrying out each task.

On the one hand, acceptability judgments evaluate the degree of conscious acceptance that the speakers of a linguistic community show. In this case, the judgment on noun phrases that are presented with gender morphology variants that do not correspond to the binary paradigm of Spanish (-o or -a). This task, in that sense, supposes a voluntary decision, on which a number 
of beliefs operate. Not only gender representations and stereotypes, but also linguistic ideologies and dominant discursive matrices, which in turn construct frameworks of dominant common sense (MORENO CABRERA, 2008; PÉREZ; MORAGAS, 2020; SAYAGO, 2019). An acceptability judgments task involves not only processes and mental representations in an implicit way, but also linguistic norms and prescriptions imposed by formal institutions, beyond the usual linguistic uses and speakers' daily lives.

A sentence comprehension task in which not only the response type but also the times required to carry out the comprehension are measured, instead, aims to study automatic psycholinguistic processes, many of them outside executive control and separated from the aware judgments of the speakers. This is how it is possible to evaluate representations manipulated cognitively in an implicit way when we process language. Beyond whether we believe that a morphological variant is more or less valid for Spanish, if we can understand it adequately and without high processing cost, we have backup data to refute that there are strictly (psycho)linguistic obstacles that block its use or its adequate comprehension.

Given this general framework, the results reported in this work are especially relevant. The two experiments presented here show, individually, novel data on the use and comprehension of non-binary morphological variants in Spanish. These specific findings have been discussed in

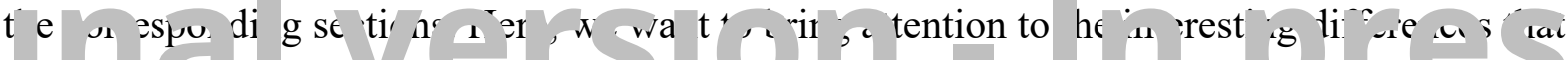
we nave found uue to the task and tire underıyng process that eacin inipose. As we could see in Experiment 1, the non-binary variants (-x and -e) continue to generate less acceptance than the generic masculine. Above all, men show more rejection of non-binary forms and, in general, this rejection is observed on role names that have a strong gender bias because they are associated with firm stereotypes -i.e. plumbers-. However, when what is asked is not a judgment but rather the reading and comprehension of a sentence, for which subjects have to indicate the possible reference, the pattern of results changes. Non-binary variants are more precise -they do not offer ambiguity about their reference- and they are processed without extra cognitive cost compared to the generic masculine. In other words, when conscious beliefs about gender representations and linguistic ideologies are at stake, speakers exhibit very different explicit positions -even in some cases opposite- than when they process language, without this process being under their executive and conscious control.

There is, however, an interesting point of contact between the results found in the two tasks. Role names with high stereotipicality always behave in a particular way. Just as non-binary forms are less accepted in these cases, the processing of these phrases, when presented in the generic masculine condition, produces a significant bias toward an exclusively male reference. 
Instead, mixed referencing is only consistently enabled when presented under conditions with non-binary variants [-x] or [-e]. This seems to be supporting the same phenomenon: when there is a very strong gender bias on the possible references of a role name, there are at least two projections. On the one hand, it is less frequent and, therefore, less accepted a phrase that marks non-binary gender in these nouns -i.e. les plomeres [the plumbers.NB]-. Simultaneously, the absence of that gender marker makes invisible the possibility that a group of people who practice plumbing could be formed by both male and female plumbers. This puts us before the classic paradoxical dilemma in many studies that analyze the relationship between thought and language. What comes first? There are not many female plumbers, so when people read los plomeros [the plumbers.MASC] they skew their representations toward men exclusively much more than with los niños (the boys)-? Or, vice versa, not being able to name precisely with a generic phrase people who practice plumbing regardless of gender, generate an inadequate representation that there are only male plumbers, making invisible a part of this group? In other words, if we began to use les plomeres [the plumbers.NB] as a generic unambiguous form for groups where not all identify with the male gender, could we begin to generate representations of female plumbers, enabling the possibility of deconstructing and denaturing categorical stereotypes?

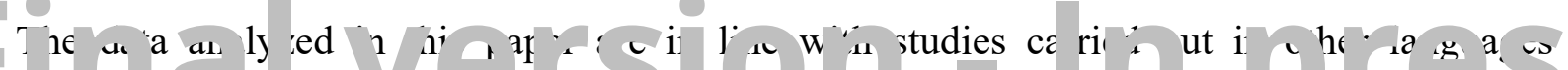
(NAUHMANN, BOhNEK, 2614; LEAPEN, 2014, SATO; GrGAX; JABNIEL, 2010; SCZESNY; MOSER; WOOD, 2015; VIGLIOCCO et al., 2005) regarding the consistent and stable biases that can be projected from the use of certain linguistic forms toward the mental representations that we handle about the world and the relationships that exist in it. In this case, the data in Spanish also indicate that the morphological variant known as generic masculine, which in theory would be able to refer and generate representations of groups with non-uniform gender, does not work strictly like that. Instead, it generates biases with respect to that reference heavily dependent on gender stereotypes linked to role names. But, in addition, we were able to show that non-binary morphological variants do not imply higher processing costs or obstacles in comprehension. On the contrary, they result in more precise ways than the generic masculine to name, refer and represent the diversity of genders that can be found within a group of people.

Without wishing to close the question about what comes first, our data show that the use of non-binary forms can adequately make this diversity visible, while showing that the barriers to their use do not come strictly from the system of language or the cognitive mechanisms that underlie its processing. 


\title{
BINÁRIO OU NÃO BINÁRIO? MORFOLOGIA DE GÊNERO EM ESPANHOL: DIFERENÇAS DEPENDENTES DE TAREFAS
}

\begin{abstract}
RESUMO
Existem evidências empíricas em diferentes línguas sobre como a computação da morfologia de gênero durante o processamento psicolingüístico afeta a conformação das representações do sexo e gênero. Entretanto, não há evidências empíricas sobre o processamento de variantes morfológicas não-binárias em espanhol (-x ou -e) em contraste com a variante genérica masculina (-o). Para analisar este fenômeno, realizamos dois experimentos: uma tarefa de julgamento de aceitabilidade e uma tarefa de compreensão de orações para analisar o processamento online. Os resultados mostram diferenças dependentes das tarefas, ou seja, nos processos subjacentes envolvidos em cada uma delas. Nos julgamentos de aceitabilidade, que envolvem processos estratégicos mediados por crenças e normas linguísticas, o genérico masculino é mais aceitável para se referir a grupos mistos. Na tarefa de compreensão de orações, que investiga processos automáticos e representações implícitas, as formas não binárias provocaram consistentemente uma referência a grupos mistos e os tempos de resposta indicaram que estas variantes morfológicas não implicam um custo de processamento mais alto do que o genérico masculino.
\end{abstract}

PALAVRAS-CHAVE: Psicolinguística. Gênero. Morfologia. Estereótipos de gênero.

hErEnErivias
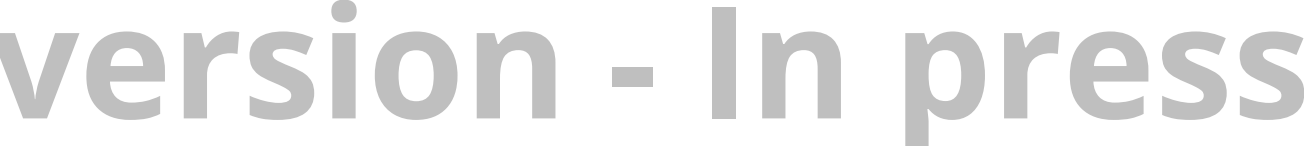

BAAYEN, H.; MILIN, P. Analyzing Reaction Times. International Journal of Psychological Research, Medellín, v.3, n.2, p.12-28, 2010.

BARR, D. J.; LEVY, R.; SCHEEPERS, C.; TILY, H. J. Random effects structure for confirmatory hypothesis testing: Keep it maximal. Journal of Memory and Language, Cambridge, v.68, n.3, p.255-278, 2013.

BARTÓN, K. MuMIn: Multi-Model Inference. R package version 1.43.17. 2020. Available on: $<$ https://CRAN.R-project.org/package=MuMIn $>$. Consulted on: 23 nov. 2020.

BATES, D.; MAECHLER, M.; BOLKER, B.; WALKER, S. Fitting Linear Mixed-Effects Models Using lme4. Journal of Statistical Software, Los Angeles, v.67, n.1, p.1-48, 2015.

BRADLEY, E.D. The influence of linguistic and social attitudes on grammaticality judgments of singular 'they'. Language Sciences, Amsterdam, v.78, 101272, 2020. doi: 10.1016/j.langsci.2020.101272

BRAUN, F.; SCZESNY, S.; STAHLBERG, D. Cognitive effects of masculine generics in German: An overview of empirical findings. Communications, Berlin, v.30, n.1, p.1-21, 2005. 
CACCIARI, C.; PADOVANI, R. Further evidence of gender stereotype priming in language: Semantic facilitation and inhibition in Italian role nouns. Applied Psycholinguistics, Cambridge, v.28, p.277-293, 2007.

CORBETT, G. G. Gender. Cambridge: Cambridge University Press, 1991.

ENDERSEN, A.; JANDA, L. A. Five statistical models for Likert-type experimental data on acceptability judgments. 2015. Available on: <https://ninum.uit.no/handle/10037/8007>. Consulted on: 23 nov. 2020.

COUSINEAU, D.; CHARTIER, S. Outliers Detection and Treatment: A review. International Journal of Psychological Research, Medellín, v.3, n.1, p.58-67, 2010.

DIXON, J. The question of genres. In REID, I. (Ed). The place of genre in learning: Current debates. Victoria: Typereader Publications, 1987, p.9-21.

EVERETT, G. Linguistic relativity: Evidence across languages and cognitive domains. Berlín: De Gruyter Mouton, 2013.

FLAHERTY, M. How a language gender system creeps into perception. Cross-cultural Psychology, New York, v.32, n.1, p.18-31, 2001.

GYGAX, P. M.; ELMINGER, D.; ZUFFEREY, S.; GARNHAN, A; SCZESNY, S.; VON STOCKHAUSEN, L.; BRAUN, F.; OAKHILL, J. A language index of grammatical gender dimensions to study the impact of grammatical gender on the way we perceive women and men. Frontiers n Psycholnoy, Lausanne, v. 10, 1604, 2019. do 10.3389/fnsvg.2019.01604

GYGAX, 1., GABRıL, U. Can a group ur musicians be cumposed o wonıen? uenenc interpretation of French masculine role names in the absence and presence of feminine forms. Swiss Journal of Psychology, Bern, v.67, n.3, p.143-151, 2008.

GYGAX, P.; GABRIEL, U.; SARRASIN, O.; OAKHILL, J.; GARNHAM, A. Generically intended, but specifically interpreted: When beauticians, musicians, and mechanics are all men. Language and Cognitive Processes, Oxon, v.23, n.3, p.464-485, 2008.

HENRICH, J.; HEINE, S.; NORENZAYAN, A. The weirdest people in the world? Behavioral and Brain Sciences, 33(2-3), p. 61-83, 2010. doi:10.1017/S0140525X0999152X

IMAI, M.; SCHALK, L.; SAALBACH, H.; OKADA, H. All giraffes have female-specific properties: Influence of grammatical gender on deductive reasoning about sex-specific properties in German speakers. Cognitive Science: A Multidisciplinary Journal, Seattle, v.38, p.514-536, 2014.

JIMÉNEZ RODRIGO, M.L.; ONSALO, M.L.; TRAVERSO CORTÉS, J. Lenguaje no sexista y barreras a su utilización. Un estudio en el ámbito universitario. Revista de Investigación en Educación, Vigo, v.9, n.2, p.174-183, 2011.

KAUFMANN, C.; BOHNER, G. Masculine generics and gender-aware alternatives in Spanish. IZGOnZeit. Interdisziplinären Zentrums für Geschlechterforschung (IZG), Bielefeld, p.817, 2014. 
KONISHI, T. The semantics of grammatical gender: A cross-cultural study. Journal of Psycholinguistic Research, New York, v.22, p.519-534, 1993.

KUZNETSOVA, A.; BROCKHOFF, P. B.; CHRISTENSEN, R. H. B. "LmerTest Package: Tests in Linear Mixed Effects Models". Journal of Statistical Software, Los Angeles, v.82, n.13, p.1-26, 2017.

LEAPER, C. Gender similarities and differences in language. En HOLTGRAVES, T. M. (Ed). The Oxford handbook of language and social psychology. Oxford: Oxford University Press, 2014.

LUCY, J. A. The scope of linguistic relativity: An analysis and review of empirical research. In GUMPERZ, J. J.; LEVINSON, S. C. (Eds). Rethinking linguistic relativity. Cambridge: Cambridge University Press, 1996, p.37-69.

MACIUSZEK, J.; POLAK, M.; ŚWIĄTKOWSKA, N. Grammatical gender influences semantic categorization and implicit cognition in Polish. Frontiers in Psychology, Lausanne, v.10, 2208, 2019. doi: 10.3389/fpsyg.2019.02208

MISERSKY, J.; MAJID, A.; SNIJDERS, T. M. Grammatical gender in German influences how role-nouns are interpreted: Evidence from ERPs. Discourse Processes, New York, v.56, n. 8, p.643-654, 2019.

MORENO CABRERA, J.C. Gramáticos y academias. Para una sociología del conocimiento at las lenguas. rbor. Ciencia. pensamiento y cultura, Madri , v. 731, 519-528, 2008.

IÉKEZ, S.ı., MORAuAS, r. Lenguaje incrusivo: Inalestares y resisten as eir el unscurso conservador. In KALINOWSKI, S.; GASPARI, J.; PÉREZ, S.I.; MORAGAS, F. Apuntes sobre lenguaje no sexista e inclusivo. Rosario: UNR Editora, 2020, p.69-96.

PINKER, S. El instinto del lenguaje. Madrid: Alianza, 1999.

PRENTICE, D. A. Do language reforms change our way of thinking? Journal of Language and Social Psychology, New York, v.13, n.1, p.3-19, 1994.

PREWITT-FREILINO, J.L.; CASWELL, T.A.; LAAKSO, E.K. The gendering of language: a comparison of gender equality in countries with gendered, natural gender, and genderless languages. Sex Roles, New York, v.66, p.268-281, 2012.

R CORE TEAM. R: A language and environment for statistical computing. Vienna: R Foundation for Statistical Computing, 2021. Available on: <https://www.R-project.org/>. Consulted on: 9 dic. 2021.

RATCLIFF, R. Methods with Dealing with Reaction Time Outliers. Psychological Bulletin, Washington, v.114, n.3, p.510-532, 1993.

SAALBACH, H.; IMAI, M.; SCHALK, L. Grammatical gender and inferences about biological properties in German-speaking children. Cognitive Science: A Multidisciplinary Journal, Seattle, v.36, p.1251-1267, 2012. 
SAPIR, E. An introduction to the study of speech. New York: Harcourt, Brace, 1921.

SATO, A.; GYGAX, P.; GABRIEL, U. Gauging the Impact of Gender Grammaticization in Different Languages: Application of a Linguistic-Visual Paradigm. Frontiers in Psychology, Lausanne, v.7, 140, 2016. doi: 10.3389/fpsyg.2016.00140

SAYAGO, S. Apuntes sociolingüísticos sobre el lenguaje inclusivo. Revista científica de la red de carreras de Comunicación Social, n.9, 2019. doi: 10.24215/24517836e015

SCHAD, D. J.; VASISHTH, S.; HOHENSTEIN, S.; KLIEGL, R. How to capitalize on a priori contrasts in linear (mixed) models: A tutorial. Journal of Memory and Language, Cambridge, v.110, n.104038, 2020.

SCZESNY, S.; MOSER, F.; WOOD, W. Beyond Sexist Beliefs: How Do People Decide to Use Gender-Inclusive Language? Personality and Social Psychology Bulletin, New York, v.41, n.7, p.943-954, 2015.

SCOTTO, S.C.; PÉREZ, D.I. Relatividad lingüística, gramáticas de género y lenguaje inclusivo: algunas consideraciones. Análisis Filosófico, Buenos Aires, v.40, n.1, p.5-39, 2020.

SEGEL, E.; BORODITSKY, L. Grammar in art. Frontiers in Psychology, Lausanne, v.1, 244, 2011. doi: 10.3389/fpsyg.2010.00244

SERA, M.; ELIEF, C.; FORBES, J.; BURCH, M. C.; RODRIGUEZ, W.; DUBOIS, D. P. When language iffects cognition and when it does not: an analy is of grammatical gender and

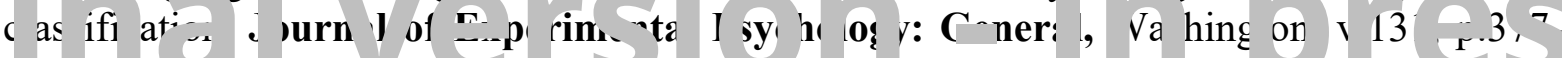
397,2602 .

SLOBIN, D. Learning to think for speaking: Native language, cognition, and rhetorical style. Pragmatics, Amsterdam, v.1, n.1, p.7-25, 1991.

SLOBIN, D. From 'Thought and Language' to 'Thinking for Speaking'. In LEVINSON, S. C.; GUMPERZ, J. J. (Eds). Rethinking linguistic relativity. Cambridge: Cambridge University Press, 1996, p.70-96.

STAHLBERG, D.; BRAUN, F.; IRMEN, L.; SCZESNY, S. Representation of the sexes in language. In FIEDLER, K. (Ed). Frontiers of social psychology. Social communication. New York: Psychology Press, 2007, p.163-187.

VIGLIOCCO, G.; VINSON, D.; PAGANELLI, F.; DWORZYNSKI, K. Grammatical Gender Effects on Cognition: Implications for Language Learning and Language Use. Journal of Experimental Psychology: General, Washington, v.134, p.501-520, 2005.

WHORF, B. L. Language, thought and reality. New York: The MIT Press, 1956.

ZEHR, J.; SCHWARZ, F. PennController for Internet Based Experiments (IBEX). 2018. doi: 10.17605/OSF.IO/MD832 
ZLATEV, J.; BLOMBERG, J. Language may indeed influence thought. Frontiers in psychology, Lausanne, v.6, 1631, 2015. doi: 10.3389/fpsyg.2015.01631

ZUNINO, G. M.; STETIE, N. A. Procesamiento de formas no binarias en español: relación entre el uso voluntario y la comprensión. Submitted. 